\title{
A simple and universal strategy for preparing external stress-free two-way shape memory polymers by making use of the chemical crosslinkages derived from peroxide initiator
}

\author{
L. F. Fan ${ }^{1,2}$, Y. N. Huang 2 , M. Z. Rong ${ }^{2}$, M. Q. Zhang ${ }^{2 *}$ \\ ${ }^{1}$ School of Textile Materials and Engineering, Wuyi University, Jiangmen, 529020 Guangdong, P. R. China \\ ${ }^{2}$ Key Laboratory for Polymeric Composite and Functional Materials of Ministry of Education, GD HPPC Lab, School of \\ Chemistry, Sun Yat-sen University, 510275 Guangzhou, P. R. China
}

Received 20 August 2019; accepted in revised form 7 October 2019

\begin{abstract}
In the present work, a new strategy for preparing authentic two-way shape memory polymer was proposed by using a conventional crosslinked polyurethane (PU) containing crystalline poly( $\varepsilon$-caprolactone) (PCL) as the proof-ofconcept material. Lauroyl peroxide (LPO) was added as a chemical crosslinker for inducing secondary crosslinking during the programming. Having been stretched and heat treated without additional ingredients and chemicals, the trained PU showed the desired two-way shape memory effect. The crosslinking network created by LPO was successfully converted into internal stress supplier, which represents the core progress of this research. As the temperature changed, the reversible melting/re-crystallization of the crystalline phases elaborately cooperated with the compressed crosslinking network, leading to the implementation of two-way shape memory effect. Through the optimization of the LPO quality, an average reversible strain of up to $\sim 21 \%$ in the direction of stretching was measured. In principle, all semi-crystalline polymers can be imparted with two-way shape memory effect following the above-proposed method. Given the great convenience of material selection, preparation, programming and application, the current research may have opened a new way for the production and usage of the smart materials in practice.
\end{abstract}

Keywords: smart polymers, two-way shape memory effect, external stress-free reversible shape memory effect, polyurethane, peroxidation initiator

\section{Introduction}

Shape memory polymers (SMPs) [1-4] can remember one or more temporary deformations and recover to their permanent shapes under certain external stimuli. Compared to one-way SMPs, two-way SMPs have attracted increasing attentions in recent years, mainly because the latter can reversibly morph so that they can be possibly used in soft robots [5-11], actuators [12-14], artificial muscles [15-19], shape changing substrates [20-24], intelligent fibers [25], $4 \mathrm{D}$ printing [26, 27], etc. According to the criterion whether external stress is necessary for operation, the two-way shape memory effect (SME) is classified into quasi two-way shape memory effect [2843] and true two-way shape memory effect [44-74]. Due to the difficulty of application of external stress in practical usage, true two-way shape memory effect is more favorable.

The key issue for preparing a two-way shape memory semicrystalline polymer capable of working in the absence of applied force lies in the introduction of internal stress provider. It plays the same role as the external stress in the case of quasi two-way SMPs [28-43] and closely cooperates with the crystalline

"Corresponding author, e-mail: ceszmq@mail.sysu.edu.cn (C) BME-PT 
phase when temperature changes, inducing oriented recrystallization of the melted phase during cooling and restoring mechanical energy during warming up. So far, the reported internal stress providers include crosslinking networks [53-57], higher $T_{\mathrm{m}}$ crystalline phases [61-72], H-bonds [58, 73] and uneven stress relaxation [56]. The internal stress providers based on crosslinking networks [53-57] seem to have broader applicability. They can make full use of the switching phases (i.e. crystal regions, relative to the case of higher $T_{\mathrm{m}}$ crystalline phases [61-72]), apply to the crystalline polymers without hydrogen bonds (relative to the case of H-bonds [58, 73]), and survive without the need of incorporating dynamic reversible bonds to the macromolecular backbones (relative to the case of uneven stress relaxation [56]).

It is worth noting that, however, the external stressfree two-way SMPs with crosslinking networks as internal stress providers used to experience twostage crosslinking for remembering the permanent and temporary shapes, respectively. The second stage of crosslinking, which proceeds during programming, involves a variety of chemical reactions specific to different polymer matrices. As a result, popularity of the techniques in industrial production has to be limited.

Peroxides are common crosslinking agents for polymers no matter whether they are saturated or unsaturated [75-77], but there have not yet been works on two-way SMPs employing peroxides for building up internal stress providers, to the best of our knowledge. In this context, we decide to explore the possibility of offering a simple and universal solution by taking advantage of peroxide crosslinking agent. That is, during the programming of a crosslinked crystalline polymer, the oriented molten molecule chains are crosslinked by the decomposed peroxides and a second chemical network is established. The joint action of the temperature-induced reversible bi-directional deformations of the crystalline phases and compressed crosslinking networks accompanying melting and orientated recrystallization of the polymer matrix would thus realize two-way shape memory effect (Figure 1). If the above thinking proves to be feasible, two-way SMPs could be easily fabricated without using complicated reactions or dynamic reversible chemistry or particular polymer species. Hereinafter, the proof-of-concept poly( $\varepsilon$-caprolactone) (PCL)-based crosslinked polyurethane (PU, Figure 2), in which the aforesaid secondary crosslinkages are constructed by lauroyl peroxide (LPO), is studied in detail.

\section{Experimental}

\subsection{Materials}

Hexamethylene diisocyanate (HDI, 99\%), 1,4-butanediol (BDO, 99\%), dibutyltin dilaurate (DBTDL, 95\%), trimethylolpropane tris(3-mercaptopropionate)
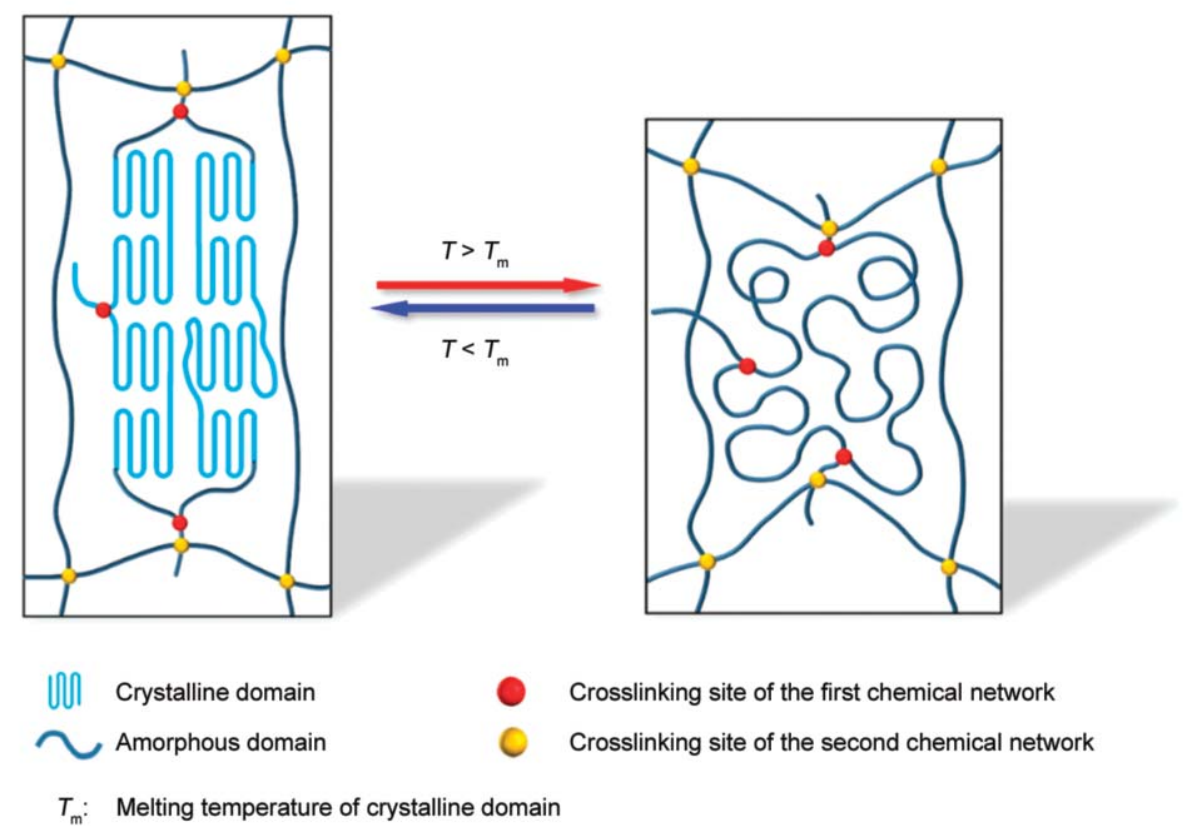

Crosslinking site of the first chemical network

Crosslinking site of the second chemical network

$T_{\mathrm{m}}$ : Melting temperature of crystalline domain

Figure 1. Mechanism of the external stress-free two-way shape memory polymer with the secondary crosslinking network as internal stress provider. 


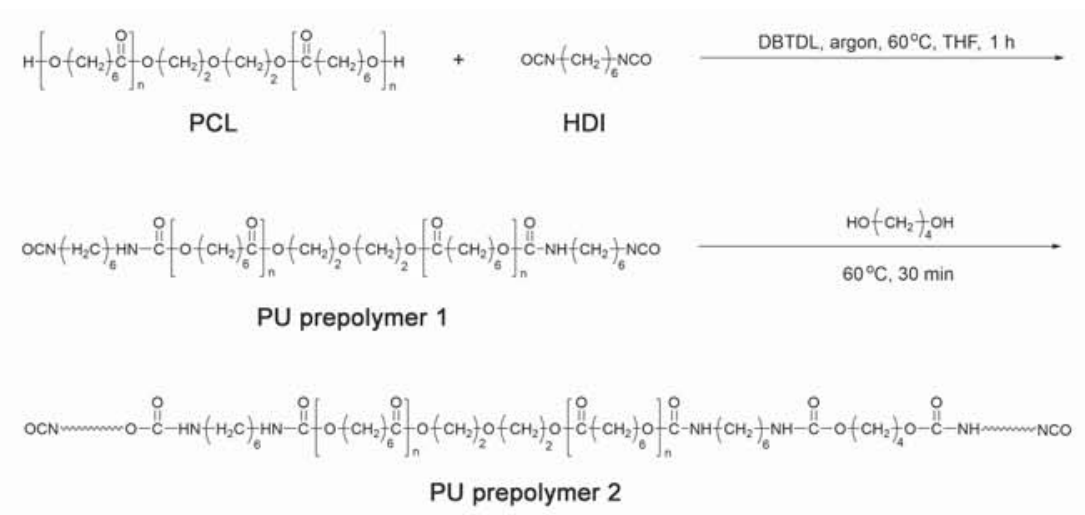
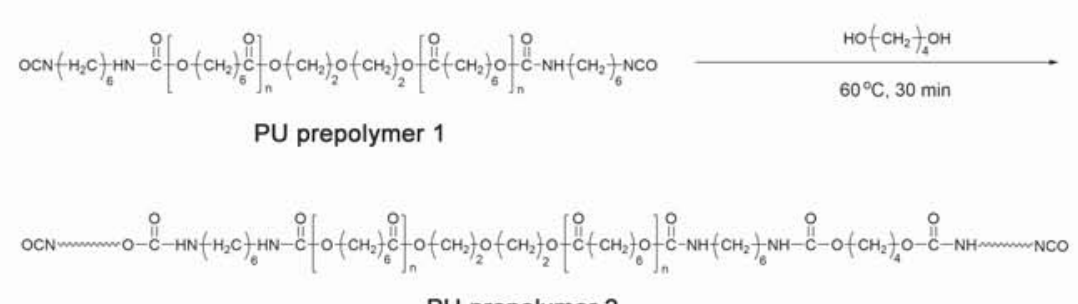

a)

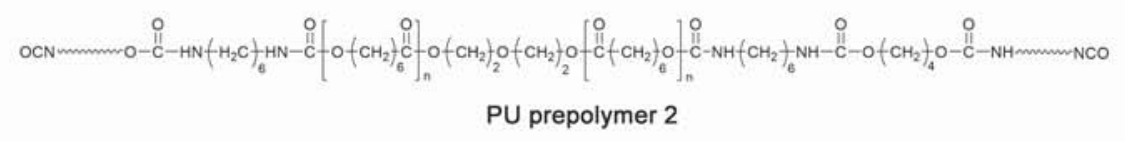
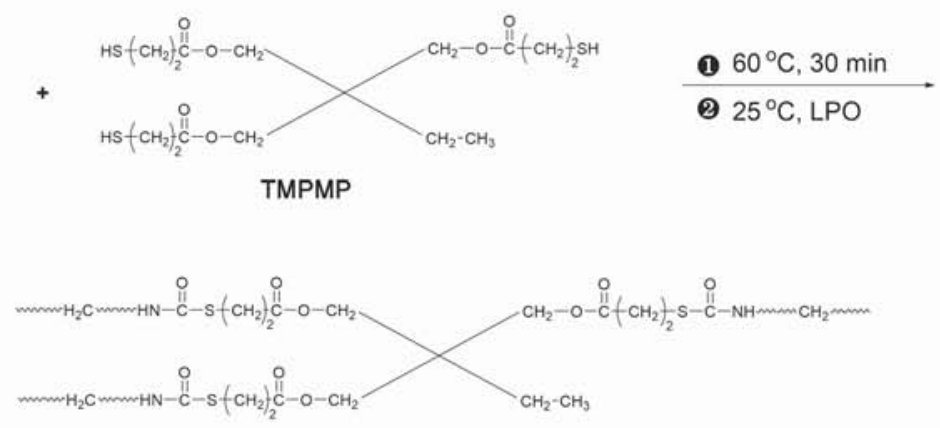

b)

Crosslinked PU including LPO

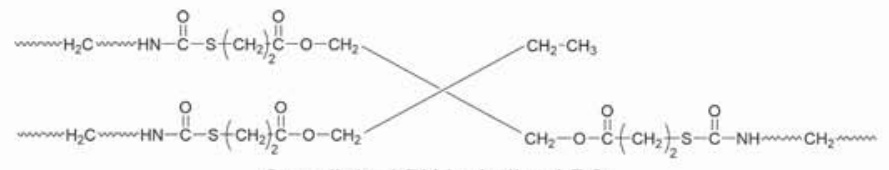

Crosslinked PU including LPO

$80^{\circ} \mathrm{C}, 8 \mathrm{~h}$

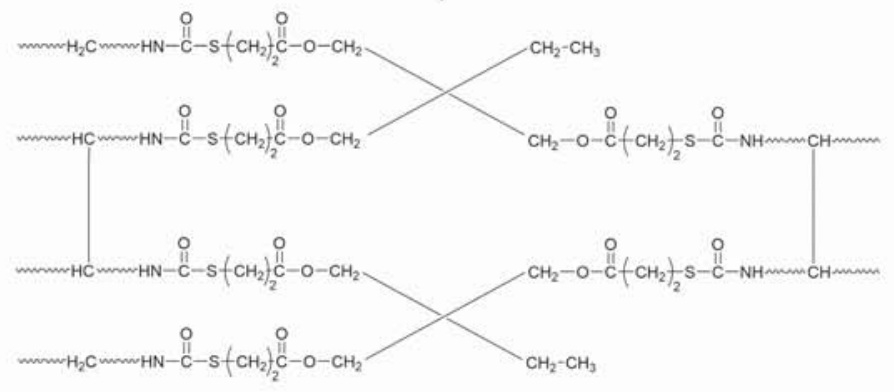

c)

Figure 2. (a) Synthesis of PU prepolymer. (b) Crosslinking of PU prepolymer by TMPMP. (c) Secondary crosslinking of PU by LPO. The hydrogens on the methylene groups are stripped by the oxygen free radicals from the decomposed LPO and new chemical crosslinking sites are formed by the termination of carbon free radicals.

(TMPMP), and lauroyl peroxide (LPO, 98\%) were lactone diol (PCL 3000, $M_{\mathrm{n}}=3000 \mathrm{~g} / \mathrm{mol}$ ) was suppurchased from Adamas Reagent, China. Polycapro- $\quad$ plied by Daicel Chemical Industries, Japan. 


\subsection{Characterization}

Spectra of proton nuclear magnetic resonance $\left({ }^{1} \mathrm{H}\right.$ NMR) were measured by an AVANCE III (400 MHz, Bruker, Germany) with dimethyl sulfoxide- $d_{6}$ as the solvent.

Fourier transform infrared (FTIR) spectra were recorded by a Nexus 670 spectrometer (Thermo Nicolet, USA). The orientation of the polymers was characterized in terms of dichroism of $\delta\left(-\mathrm{CH}_{2}-\right)$ absorption of PCL at about $1470 \mathrm{~cm}^{-1}$ [78]. The extent of anisotropy in the oriented PU was assessed by the corresponding dichroic ratio, $R=A_{\|} / A_{\perp}$, where $A_{\|}$ and $A_{\perp}$ are the absorption intensities measured with radiation polarized parallel and perpendicular to the stretching direction, respectively. Accordingly, $(R-1) /(R+2)$ gives a measure of the orientation degree $[78,79]$. Prior to the measurements, two background single-beam spectra were recorded with the polarizers parallel and perpendicular to the elongation direction with the same experimental parameters, respectively.

Molecular weight was determined at ambient temperature using a Waters Breeze gel permeation chromatography (GPC) system with tetrahydrofuran (THF) as eluent and polystyrene standards for calibration.

The melting and crystallization behaviors were measured using differential scanning calorimeter (DSC, Q10, TA Instruments, USA) with nitrogen as the purge gas and an electric intracooler as the cooling source. The temperature was cyclically controlled. For each temperature cycle, the sample was heated to $60^{\circ} \mathrm{C}$ at $3{ }^{\circ} \mathrm{C} / \mathrm{min}$, kept at $60^{\circ} \mathrm{C}$ for $2 \mathrm{~min}$, cooled down to $-20^{\circ} \mathrm{C}$ at $-3{ }^{\circ} \mathrm{C} / \mathrm{min}$, and finally kept at $-20^{\circ} \mathrm{C}$ for $2 \mathrm{~min}$.

Dynamic mechanical properties were measured with a dynamic mechanical analyzer (DMA, Q800, TA Instruments, USA) at $1 \mathrm{~Hz}$. Controlled forced mode was applied to measure the variation in specimen length at zero force. The temperature profile was the same as that of DSC measurement. According to the equation of state for rubber elasticity, crosslink density, $v$, was calculated from Equation (1) [80]:

$v=\frac{E^{\prime}}{6 R T}$

where $E^{\prime}$ stands for storage modulus at rubbery plateau zone, $R$ gas constant, and $T$ absolute temperature, respectively. In this work, $E^{\prime}$ values at $T=$ $T_{\mathrm{g}}+30^{\circ} \mathrm{C}$ were used for the calculation.
Wide angle X-ray diffraction (WAXD) patterns were recorded by a PANalytical Empyrean X-ray diffractometer with $\mathrm{Cu} \mathrm{K} \alpha$ radiation. The scanning range of Bragg $2 \theta$ angle was from 5 to $30^{\circ}$ with a scanning rate of $3 \% \mathrm{~min}$.

\subsection{Synthesis of $P U$ and the control}

PCL (30.0 g, $0.01 \mathrm{~mol})$, HDI (3.7 g, $0.022 \mathrm{~mol}$ ) and two drops of DBTDL were dissolved in tetrahydrofuran (THF, $150 \mathrm{ml}$ ). The mixture was heated to $60^{\circ} \mathrm{C}$ and stirred in argon for $1 \mathrm{~h}$ (Figure 2a). BDO $(0.22 \mathrm{~g}, 0.0024 \mathrm{~mol})$ was incorporated under stirring for $30 \mathrm{~min}$ to produce PU prepolymer 2 . Then, the crosslink agent, TMPMP $(2.55 \mathrm{~g}, 0.0064 \mathrm{~mol})$, was added with stirring for $30 \mathrm{~min}$ (Figure 2b). When the mixture was cooled down to room temperature, the peroxide crosslinking agent LPO $(0.94 \mathrm{~g}, 0.0024 \mathrm{~mol})$ was added with stirring for $30 \mathrm{~min}$. Afterwards, the mixture was poured into a polytetrafluoroethylene (PTFE) mold to remove the solvent at room temperature for $48 \mathrm{~h}$, yielding the chemically crosslinked PU sheet containing LPO.

${ }^{1} \mathrm{H}$ NMR (400 MHz, DMSO, $25^{\circ} \mathrm{C}, \delta[\mathrm{ppm}]$ ) spectra of HDI, PCL, PU prepolymer 1 and prepolymer 2: HDI $(1.34,1.56,3.35 .1 .34 \quad(4 \mathrm{H}$, $\left.\mathrm{OCN}-\left(\mathrm{CH}_{2}\right)_{2}-\left(\mathrm{CH}_{2}\right)_{2}-\left(\mathrm{CH}_{2}\right)_{2}-\mathrm{NCO}\right), 1.56 \quad(4 \mathrm{H}$, $\left.-\mathrm{CH}_{2}-\mathrm{CH}_{2}-\mathrm{NCO}\right)$, and $3.35\left(4 \mathrm{H},-\mathrm{CH}_{2}-\mathrm{CH}_{2}-\mathrm{NCO}\right)$ ); PCL $(1.30,1.53,2.28,3.98,4.34,4.48 .1 .30(4 \mathrm{nH}$, $\left.-\mathrm{CO}-\left(\mathrm{CH}_{2}\right)_{2}-\mathrm{CH}_{2}-\right), \quad 1.53 \quad(8 \mathrm{nH}$, $\left.-\mathrm{CO}-\mathrm{CH}_{2}-\mathrm{CH}_{2}-\mathrm{CH}_{2}-\mathrm{CH}_{2}-\right), 2.28\left(4 \mathrm{H},-\mathrm{CO}-\mathrm{CH}_{2}-\right)$, $3.98\left(4 \mathrm{nH},-\mathrm{CO}-\mathrm{CH}_{2}-\mathrm{CH}_{2}-\mathrm{CH}_{2}-\mathrm{CH}_{2}-\mathrm{CH}_{2}-\right), 4.34(8 \mathrm{H}$, $\left.-\mathrm{O}-\mathrm{CH}_{2}-\mathrm{CH}_{2}-\mathrm{O}-\mathrm{CH}_{2}-\mathrm{CH}_{2}-\mathrm{O}-\right)$, and $4.48(2 \mathrm{H}$, $\left.-\mathrm{CH}_{2}-\mathrm{CH}_{2}-\mathrm{OH}\right)$ ); PU prepolymer 1 (1.28, 1.52 , $2.25,3.97,6.96 .6 .96\left(\mathrm{H},-\mathrm{CO}-\mathrm{NH}-\mathrm{CH}_{2}-\right)$, and the other characteristic peaks $(1.32,1.55,2.28$ and 3.99) representing $\mathrm{CH}_{2}$ on PCL or HDI); PU prepolymer 2 $(1.28, \quad 1.52, \quad 2.25, \quad 3.97, \quad 6.96 .6 .96 \quad(\mathrm{H}$, - $\mathrm{CO}-\mathrm{NH}-\mathrm{CH}_{2}-$ ), and the other characteristic peaks (1.32, 1.55, 2.28 and 3.99) representing $\mathrm{CH}_{2}$ on PCL or HDI). FTIR spectra (KBr $\left.\left[\mathrm{cm}^{-1}\right]\right)$ of HDI, PCL, PU prepolymer 1and PU prepolymer 2: PCL (3551, 2943, 2866, 1734, and 1462); HDI (2941, 2862, 2267, and 1464); PU prepolymer 1 (3342, 2944, 2862, 2267, 1728, 1527, 1467, and 1244), and PU prepolymer 2 (3342, 2944, 2862, 2267, 1728, 1527, 1467 , and 1244).

To highlight the critical role of LPO, the control sample excluding LPO was also prepared following the above steps. 


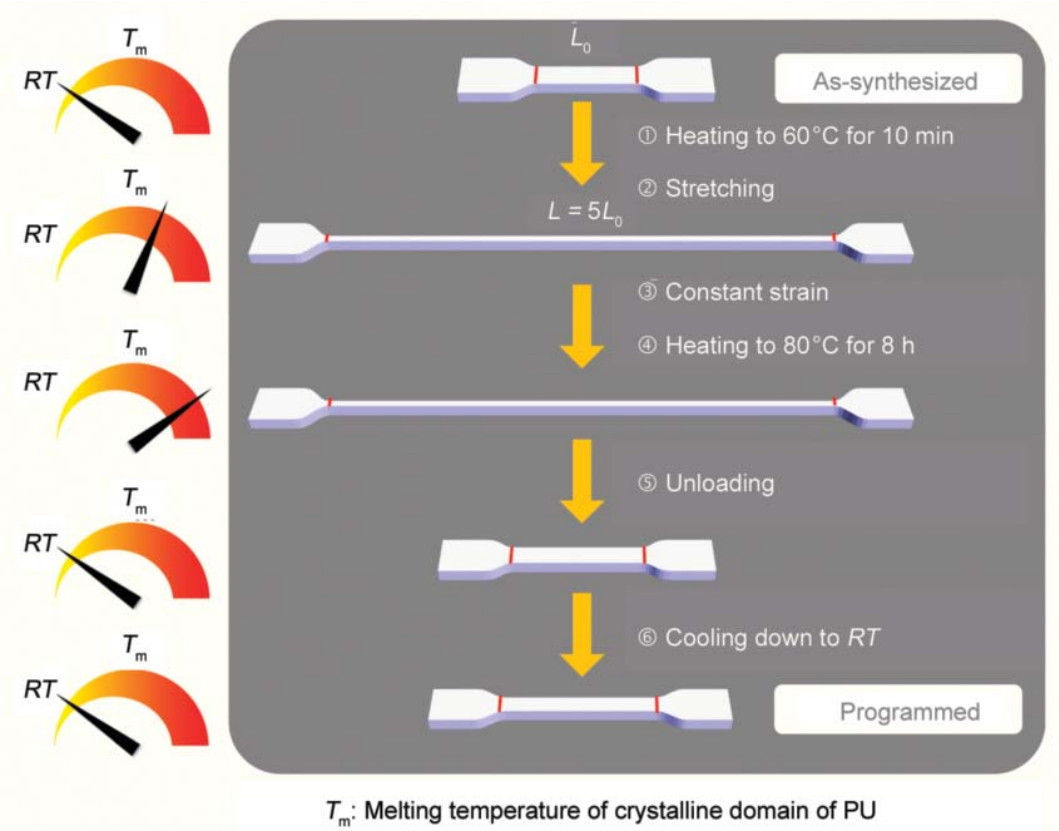

Figure 3. Programming of PU towards two-way shape-memory effect.

\subsection{Programming}

To gain the desired true two-way shape-memory effect, the as-synthesized crosslinked PU and the control were trained following the procedures depicted in Figure 3. Firstly, the dumbbell-shaped PU specimen was heated to $60^{\circ} \mathrm{C}$ for $10 \mathrm{~min}$ and stretched to 5 times the length of the original one. Then, the specimen was kept at $80^{\circ} \mathrm{C}$ for $8 \mathrm{~h}$ in $\mathrm{N}_{2}$ atmosphere under the constant strain conditions. Finally, the applied force was removed and the specimen was cooled down to $25^{\circ} \mathrm{C}$.

\section{Results and discussion}

At the beginning, structures of the designed polymers should be confirmed and characterized. The ${ }^{1}$ H NMR (Figure 4a) and FTIR (Figure 4b) spectra evidence that PU prepolymer 1 has been produced as planned, and GPC measurement further gives its $M_{\mathrm{n}}$ of $1.2 \cdot 10^{4} \mathrm{~g} / \mathrm{mol}$. When the chains of PU prepolymer 1 have been extended by BDO, the molecular weight of the resultant PU prepolymer 2 was determined to be $1.4 \cdot 10^{4} \mathrm{~g} / \mathrm{mol}$. The obviously weakened absorption of -NCO at $2267 \mathrm{~cm}^{-1}$ on the FTIR spectra of PU prepolymer 1 and prepolymer 2 (Figure $4 b$ ) as compared with that on the FTIR spectrum of HDI indicates that PCL has completely reacted with excessive HDI. In other words, sufficient -NCO groups are available for the subsequent reaction with TMPMP to create the first crosslinking network (Figure 1 and Figure 2b).
The crystalline feature of the prepared PU is characterized by WAXD (Figure 4c) and DSC (Figure 4d), respectively. The data in Table 1 demonstrate that after PCL is included in the PU chains, both $T_{\mathrm{m}}$ and $T_{\mathrm{c}}$ as well as the crystallinity of the former decrease, suggesting that the crystallization ability of PCL in PU is depressed by the hard segments [82]. Such a reduction in crystallizability is also observed after curing by LPO to produce the second crosslinking network (Figure 1 and Figure 2c). Nevertheless, the unit cell dimensions of PCL remain unchanged as the characteristic WAXD peak positions are independent of the composition (Figure 4c).

The glass transition temperature, $T_{\mathrm{g}}$, and crosslink densities of the prepared PU and the control are estimated from the DMA curves in Figure 4e and 4f. According to the peak position of $\tan \delta, T_{\mathrm{g}}$ of the programmed PU is found to be $-8.2^{\circ} \mathrm{C}$, which is higher

Table 1. Characteristic parameters of the DSC measurement of Figure 4d.

\begin{tabular}{|l|r|r|r|}
\hline \multicolumn{1}{|c|}{ Materials } & $\begin{array}{c}\boldsymbol{T}_{\mathbf{m}}{ }^{\mathbf{a})} \\
{\left[{ }^{\circ} \mathbf{C}\right]}\end{array}$ & $\begin{array}{c}\boldsymbol{T}_{\mathbf{c}}{ }^{\mathbf{b})} \\
{\left[{ }^{\circ} \mathbf{C}\right]}\end{array}$ & \multicolumn{1}{|}{$\begin{array}{l}\boldsymbol{X}_{\mathbf{c}}{ }^{\mathbf{c})} \\
{[\mathbf{\%}]}\end{array}$} \\
\hline PCL & 52.3 & 31.3 & 62.2 \\
\hline PU (as synthesized excluding LPO) & 48.0 & 8.6 & 32.9 \\
\hline PU (programmed without stretching) & 47.6 & 11.2 & 29.8 \\
\hline PU (programmed) & 47.3 & 11.7 & 31.1 \\
\hline
\end{tabular}

${ }^{\text {a) }} T_{\mathrm{m}}$ : peak endothermic temperature;

${ }^{b)} T_{\mathrm{c}}$ : peak exothermic temperature;

${ }^{\text {c) }} X_{\mathrm{c}}$ : apparent crystallinity of PCL calculated from $\Delta H_{\mathrm{f}}{ }^{\circ}$ (where $\Delta H_{\mathrm{f}}$ denotes the measured heat of fusion, and $\Delta H_{\mathrm{f}}^{\circ}$ is the heat of fusion of $100 \%$ crystalline PCL (139.5 J/g [81]). 

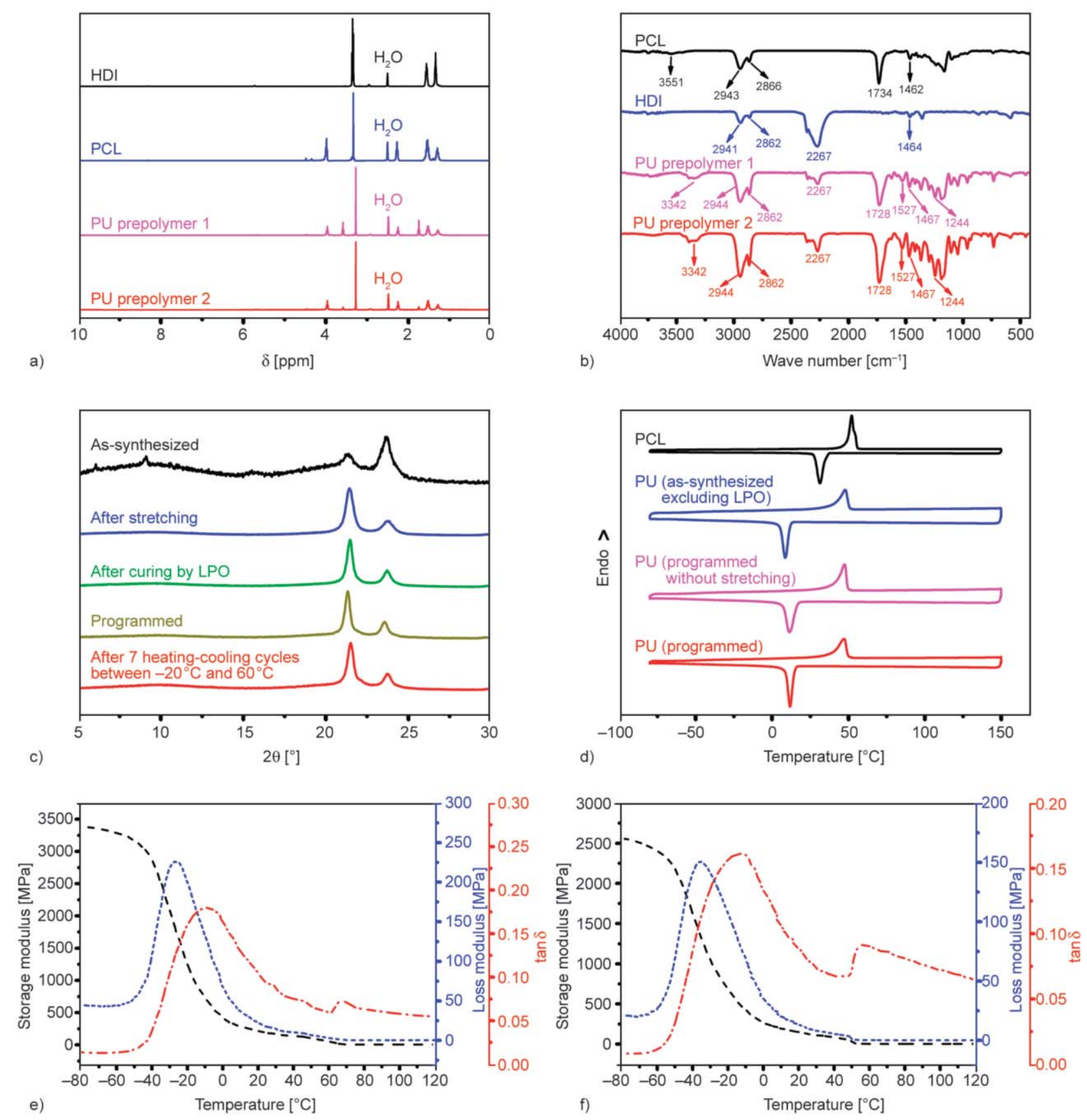

Figure 4. (a) ${ }^{1} \mathrm{H}$ NMR spectra of HDI, PCL, PU prepolymer 1 and PU prepolymer 2. (b) FTIR spectra of HDI, PCL, PU prepolymer 1 and PU prepolymer 2. (c) WAXD intensity profiles of PU: as-synthesized (original version), after stretching (step (2) in Figure 3, followed by cooling down to room temperature), after curing by LPO (step (4) in Figure 3, followed by cooling down to room temperature), programmed, and after seven heating-cooling cycles between $-20^{\circ} \mathrm{C}$ and $60^{\circ} \mathrm{C}$. (d) DSC heating and cooling scans of the programmed PU and the related materials (ramp: $3^{\circ} \mathrm{C} / \mathrm{min}$ ). DMA spectra of (e) the programmed PU and (f) the control (ramp: $3^{\circ} \mathrm{C} / \mathrm{min}$; frequency: $1 \mathrm{~Hz}$ ).

than that of the control $\left(-12.8^{\circ} \mathrm{C}\right)$. Because the secondary network is absent in the control, the higher $T_{\mathrm{g}}$ of the programmed PU manifests that an additional crosslinking network must have been established by LPO decomposition. The analysis is supported by the results of crosslinking density, which is $1.4 \cdot 10^{5} \mathrm{~mol} / \mathrm{m}^{3}$ for the programmed $\mathrm{PU}$ and $1.2 \cdot 10^{5} \mathrm{~mol} / \mathrm{m}^{3}$ for the control.
On the basis of the above fundamental analyses, the structural variations in PU accompanying the training procedures (Figure 3) for acquiring external stress-free two-way shape memory effect are discussed in the following. Initially, the specimen is heated to $60^{\circ} \mathrm{C}$ for $10 \mathrm{~min}$ (step (1) in Figure 3), which is higher than $T_{\mathrm{m}}$ of PU (Figure $4 \mathrm{~d}$ and Table 1), so that the specimen can be easily elongated (step (2) in 
Figure 3). Meantime, LPO decomposes extremely slowly because the half-life, $t_{1 / 2}$, of LPO at $60^{\circ} \mathrm{C}$ is as long as $21 \mathrm{~h} \mathrm{[83].} \mathrm{The} \mathrm{subsequent} \mathrm{heating} \mathrm{at} 80^{\circ} \mathrm{C}$ for $8 \mathrm{~h}$ at the fixed strain (step (3) in Figure 3) greatly speeds up LPO decomposition $\left(t_{1 / 2}\right.$ of LPO at $80^{\circ} \mathrm{C}=$ $1 \mathrm{~h} \mathrm{[83])} \mathrm{and} \mathrm{hence} \mathrm{leads} \mathrm{to} \mathrm{chemical} \mathrm{crosslinking}$ of the oriented macromolecular chains of PU giving birth to the second crosslinking network. Afterwards, the applied force is removed (step (4) in Figure 3) and the specimen length became shortened as a result of entropy increase induced contraction, while the second crosslinking network created by LPO decomposition keeps almost intact and tends to recover to the expanded state when it is built (i.e. step (4) in Figure 3 ). The two opposite deformations eventually result in the fact that the ultimate specimen length is significantly reduced, but slightly longer than the original one. This is because the second crosslinking network has become a compressed spring-like internal stress provider after step (5). Lastly, the specimen is cooled to room temperature, offering the programmed version (step (6) in Figure 3), while the oriented crystalline of PCL (with orientation degree of 0.19 , see Figure 5 and Table 2) is re-created under the tension exerted by the internal stress provider. In the course of step (6), the tension status of the internal stress provider is somewhat relaxed along with the expansion originating from the re-crystallization. With the help of the above training, the programmed PU should be able to implement two-way shape memory effect free of external stress. An increase of temperature of the specimen higher than $47.3^{\circ} \mathrm{C}\left(T_{\mathrm{m}}\right.$ of the PCL phase) would lead to melting of the oriented crystalline domains. Accordingly, macroscopic shrinkage would be perceived. In case the specimen is cooled to room temperature, the oriented crystalline domains would be re-generated under the guidance of the compressed internal stress provider, so that the specimen length increases. The cyclic melting and re-crystallization of the crystalline regions cooperate with the variation in the tension states (slacker and tighter tension) of the internal force provider, ensuring repeated shape transformation of the PU in the absence of applied force (Figure 1). The photos in Figure 6a prove that the consideration is true.

To quantify the two-way shape memory effect, both thermomechanical behavior and thermogram of the programmed PU are repeatedly measured between -20 and $60^{\circ} \mathrm{C}$. As shown in Figure $6 \mathrm{~b}$ and $6 \mathrm{c}$, the length contraction induced by entropy increase occurs

Table 2. Characterization of orientation of the PU specimen based on the measurement of FTIR dichroism in Figure 5.

\begin{tabular}{|l|c|c|c|c|}
\hline \multicolumn{1}{|c|}{ PU } & As-synthesized & After stretching $^{*}$ & Programmed & After 7 heating-cooling cycles between $\boldsymbol{R T}$ and 60 \\
\hline$A_{\|} \mathbf{C}^{-1.37}$ & 1.37 & 1.15 & 0.50 & 0.44 \\
\hline$A_{\perp}$ & 1.37 & 0.51 & 0.34 & 0.31 \\
\hline$R$ & 1.00 & 2.25 & 1.47 & 1.42 \\
\hline$(R-1) /(R+2)$ & 0.00 & 0.38 & 0.19 & 0.17 \\
\hline
\end{tabular}

${ }^{*}$ The specimen was deformed to a temporary shape with strain of $500 \%$ and cooled to room temperature.
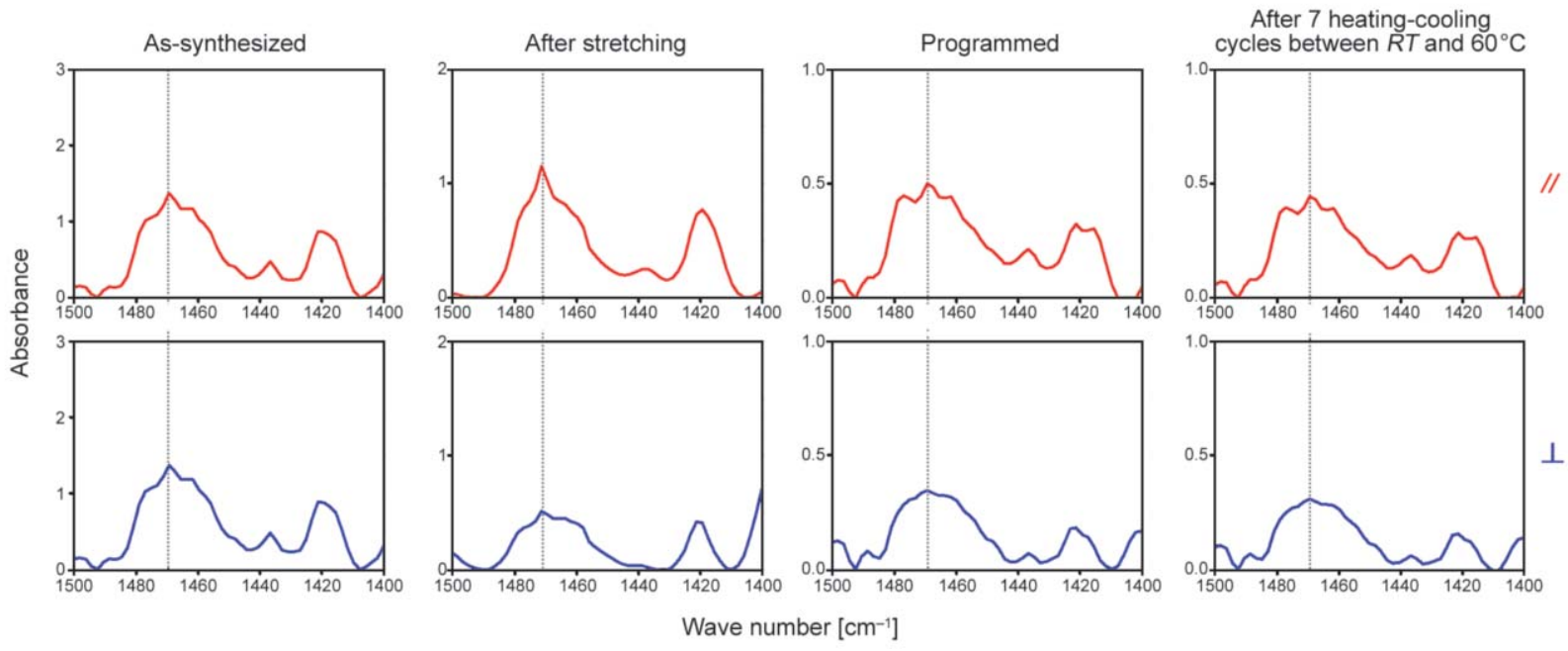

Figure 5. $\delta\left(-\mathrm{CH}_{2}-\right)$ region on the FTIR spectra of the PU specimens.

Note: The specimen measured during programming means that it was deformed to a temporary shape with strain of $500 \%$ and cooled to room temperature. 


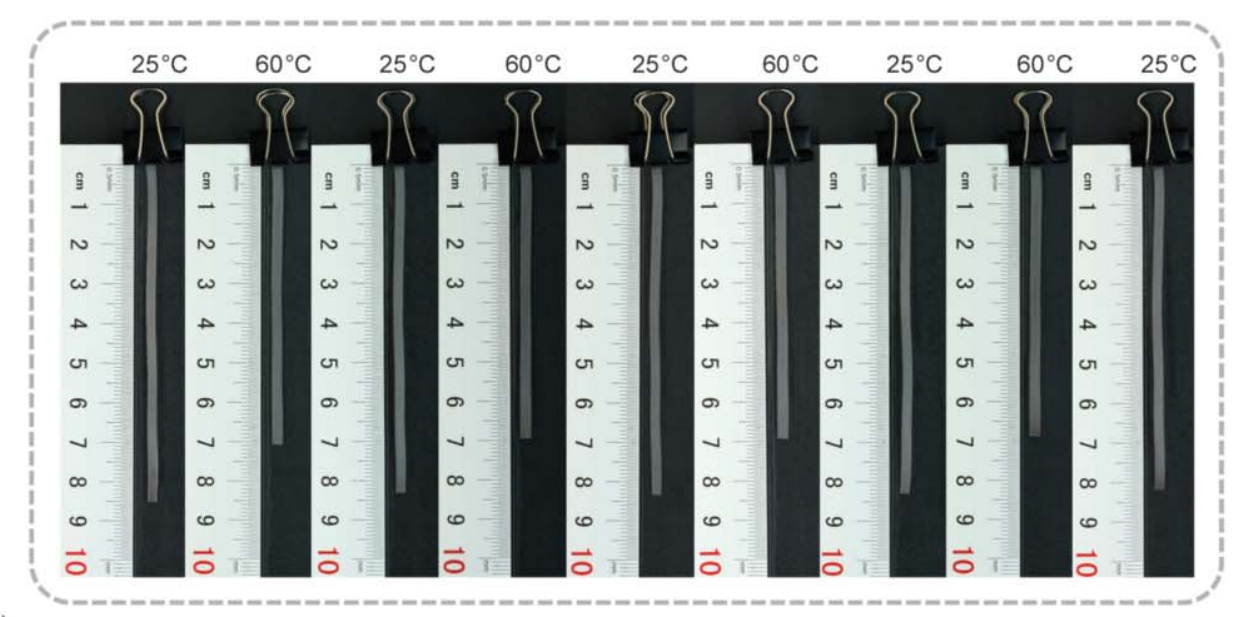

a)
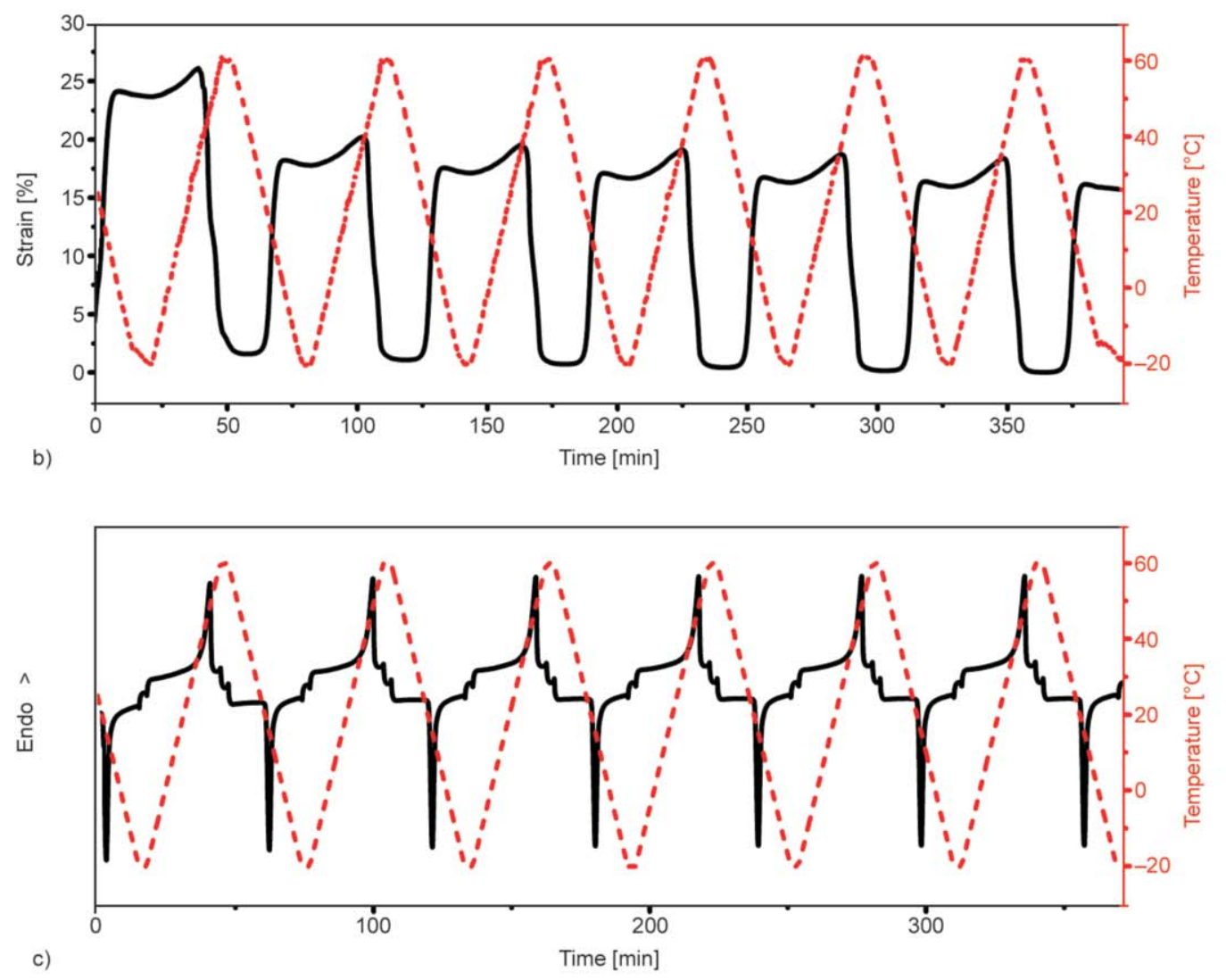

Figure 6. (a) Length variation of the programmed PU measured during heating-cooling cycles between 25 and $60^{\circ} \mathrm{C}$. (b) Twoway shape memory effect (measured by DMA) and (c) the corresponding DSC curves of the programmed PU during heating-cooling cycles between -20 and $60^{\circ} \mathrm{C}$ (ramp: $3^{\circ} \mathrm{C} / \mathrm{min}$ ). The first cycle is used to remove the thermal history and is not displayed for clarity.

when temperature exceeds $T_{\mathrm{m}}$ of PU. Soon after being cooled below $T_{\mathrm{m}}$ of PU, length increase of the specimen is detected. The bidirectional deformations are allowed to autonomously proceed along with cyclic temperature variation as expected. According to Figure $6 \mathrm{~b}$, the average reversible strain of the first three cycles is determined to be $20.9 \%$. Table 2 further shows that the value of $(R-1) /(R+2)$ of the specimen (that is related to orientation of the crystalline phases) after seven heating-cooling cycles resembles that of the as-programmed one, which suggests that the reversible shape memory effect is quite stable.

According to the mechanism of two-way shape memory effect illustrated in Figure 1, the programmed PU should be able to be reversibly bended in addition to reversible shortening. As shown in Figure 7, when a hair dryer approaches the middle of the programmed PU from the right side, the specimen 


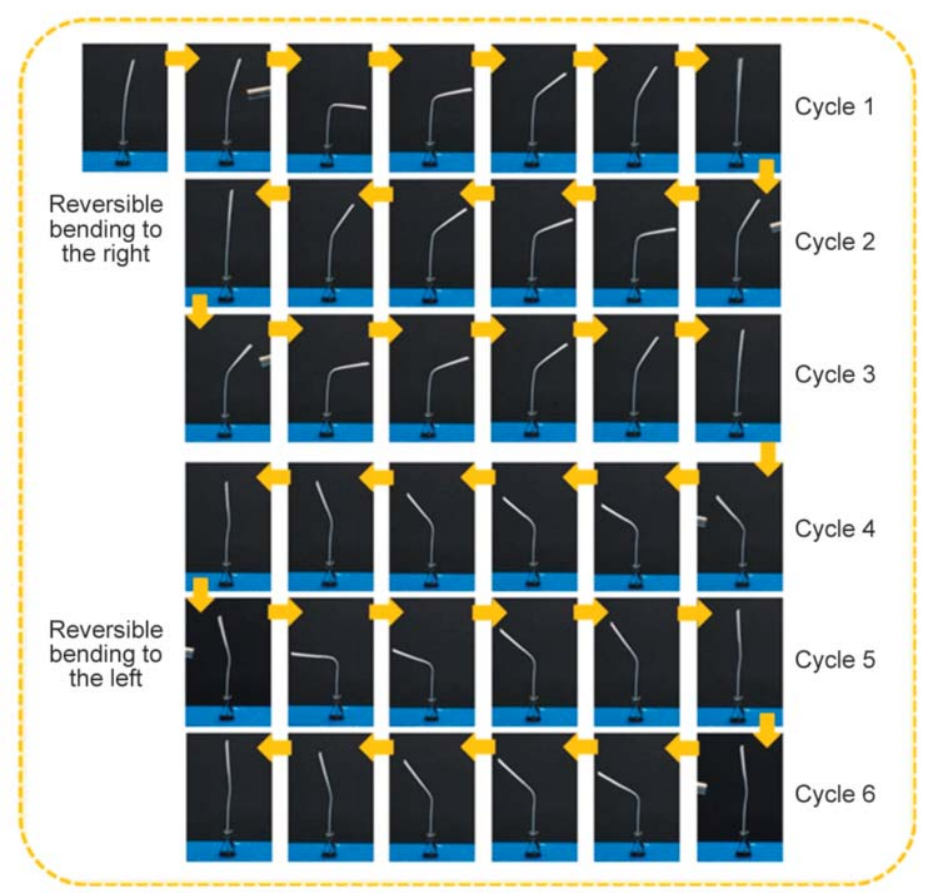

Figure 7. Reversible bending of the programmed PU subjected to repeated localized heating provided by a hair dryer.

quickly bends towards the hair dryer as the hot air out of the dryer leads to melting of the nearby crystalline phases. The portion close to the hair dryer has to contract, while the rest part keeps still, which leads to the above-mentioned bending behavior. Upon removal of the heating source, the melted part is recrystallized under the tension of the internal stress provider, and the specimen is straightened again. The same bending action can be repeated for many times due to the two-way shape memory effect. Similarly, when a specimen of the programmed PU with the two ends fixed is uniformly heated (Figure 8), the longitudinal contraction during heating is nearly invisible, but the extension during cooling results in the arch shape. This bending behavior can also be reproduced for the same reason as discussed above.

On the other hand, the two-way shape memory PU can be coupled with irreversible one-way shape memory effect through additional programming. As shown in Figure 9, when the specimen, which is reversibly deformed in the course of heating-cooling cycles, is subjected to an external tensile stress as the specimen

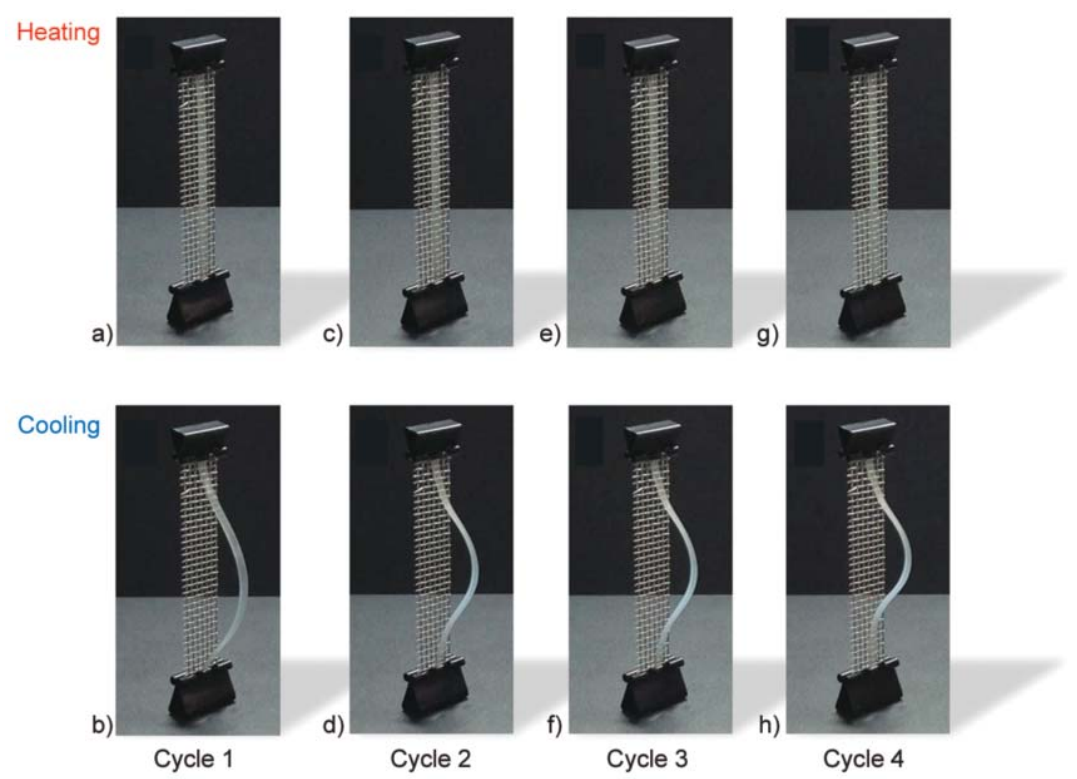

Figure 8. Reversible bending of the programmed PU specimen (with the two ends fixed) subjected to heating-cooling cycles between 60 and $25^{\circ} \mathrm{C}$. Cycling sequence: (a) $\rightarrow$ (b) $\rightarrow(\mathrm{c}) \rightarrow(\mathrm{d}) \rightarrow(\mathrm{e}) \rightarrow(\mathrm{f}) \rightarrow(\mathrm{g}) \rightarrow(\mathrm{h})$. 


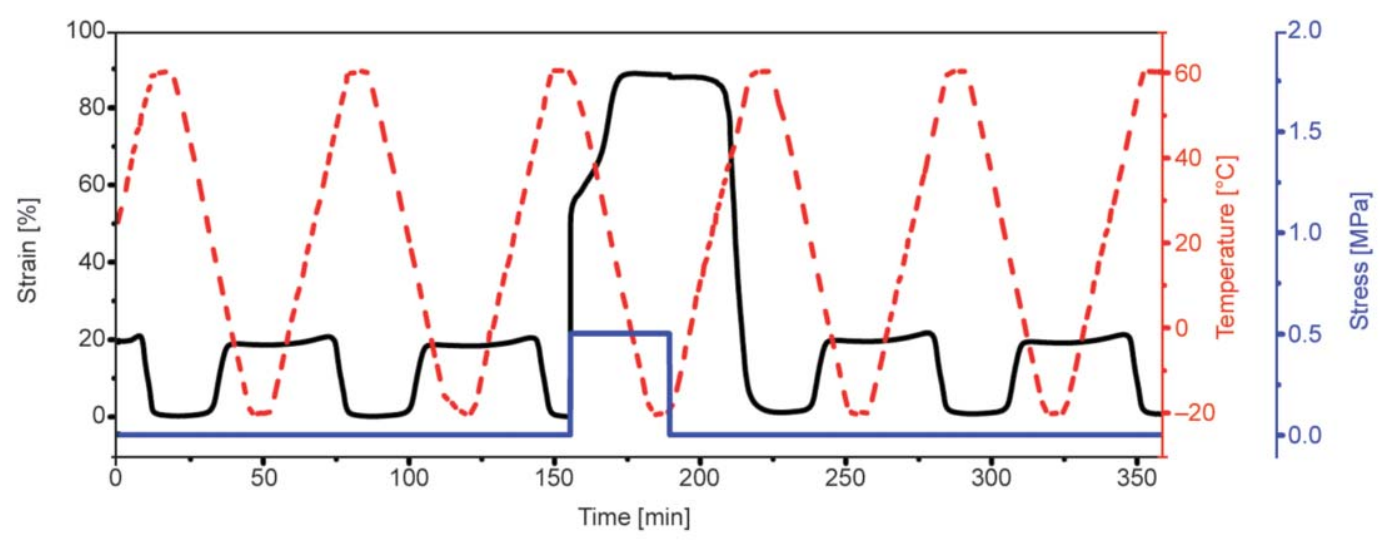

Figure 9. Thermomechanical behavior (measured by DMA) of the programmed PU during cyclic heating/cooling between -20 and $60^{\circ} \mathrm{C}$ (ramp: $3^{\circ} \mathrm{C} / \mathrm{min}$ ). An additional tensile stress of $0.50 \mathrm{MPa}$ was applied during the DMA test to impart one-way shape memory effect to the two-way shape memory PU.

Note: The amount of the additional tensile stress is optional, so long as a certain degree of tensile strain can be induced.

length becomes the shortest at $60^{\circ} \mathrm{C}$, an immediate increase in length takes place (which is favored by the fully melted crystalline phases). With further decreasing temperature from 60 to $-20^{\circ} \mathrm{C}$, the specimen keeps on being stretched and reaches a plateau. Even when the additional stress is unloaded at $-20^{\circ} \mathrm{C}$, only an insignificant reduction in the specimen length is observed. It means that a new temporary shape has been remembered by the specimen via formation of oriented crystals. During the subsequent heating from -20 to $60^{\circ} \mathrm{C}$, the specimen length is recovered from the new temporary shape, and a complete cycle of one-way shape memory effect is realized. The shape fixity, $R_{\mathrm{f}}$, and shape recovery, $R_{\mathrm{r}}$, of this one-way shape memory effect are calculated to be 99.2 and $98.7 \%$, respectively. What is more, since the additionally applied force is in the same direction as the tension offered by the internal stress provider, the two-way shape memory effect is not affected after the implementation of the one-way shape memory effect.

\section{Conclusions}

The present work proves that external stress-free reversible shape memory effect can be easily acquired by introducing the secondary crosslinking network as internal stress provider via peroxide decomposition. The merits of the proposed approach are summarized as follows. There is no strict requirement for the base material, and routine semi-crystalline polymers are qualified. The peroxide induced crosslinking reaction is controllable under conventional conditions.
Moreover, peroxides are cost-effective and have been largely used in industry. In principle, the first crosslinking network that enables the crystalline polymer to be trained above melting point can also be formed by another peroxide. It means that external stress-free two-way shape memory polymer may be obtained by adding two types of peroxides with different decomposition temperatures into the target polymer to generate the first and second crosslinking networks, respectively, which would further simplify the manufacturing.

\section{Acknowledgements}

The authors thank the support of the National Natural Science Foundation of China (Grants: 51773229, 51333008, 51673219 and 51873235), the Scientific and Technological Program of Guangdong Province (Grant: 2017A010103008), the Natural Science Foundation of Guangdong Province (Grant: 2018B030311017) and the Foundation for Distinguished Young Talents in Higher Education of Guangdong, China (2018KQNCX274).

\section{References}

[1] Yu Z. Y., Li Y., Feng Z. P., Zhang Z. H., Li P., Chen Y., Chen S. S., Li P. W., Yang Z. M.: $\mathrm{Cu}^{+}$-containing physically crosslinked chitosan hydrogels with shape memory. Express Polymer Letters, 13, 785-793 (2019).

https://doi.org/10.3144/expresspolymlett.2019.67

[2] Maksimkin A. V., Kaloshkin S. D., Zadorozhnyy M. V., Senatov F. S., Salimon A. I., Dayyoub T.: Artificial muscles based on coiled UHMWPE fibers with shape memory effect. Express Polymer Letters, 12, 1072-1080 (2018).

https://doi.org/10.3144/expresspolymlett.2018.94 
[3] Liu Y., Guo Y., Zhao J., Chen X., Zhang H., Hu G., Yu X., Zhang Z.: Carbon fiber reinforced shape memory epoxy composites with superior mechanical performances. Composites Science and Technology, 177, 4956 (2019).

https://doi.org/10.1016/j.compscitech.2019.04.014

[4] Liu Y., Zhang W., Zhang F., Leng J., Pei S., Wang L., Jia X., Cotton C., Sun B., Chou T-W.: Microstructural design for enhanced shape memory behavior of 4D printed composites based on carbon nanotube/polylactic acid filament. Composites Science and Technology, 181, 107692/1-107692/9 (2019).

https://doi.org/10.1016/j.compscitech.2019.107692

[5] Hu Y., Liu J., Chang L., Yang L., Xu A., Qi K., Lu P., Wu G., Chen W., Wu Y.: Electrically and sunlight-driven actuator with versatile biomimetic motions based on rolled carbon nanotube bilayer composite. Advanced Functional Materials, 27, 1704388/1-1704388/10 (2017). https://doi.org/10.1002/adfm.201704388

[6] Bartlett N. W., Tolley M. T., Overvelde J. T. B., Weaver J. C., Mosadegh B., Bertoldi K., Whitesides G. M., Wood R. J.: A 3D-printed, functionally graded soft robot powered by combustion. Science, 349, 161-165 (2015). https://doi.org/10.1126/science.aab0129

[7] Jiang W., Niu D., Liu H., Wang C., Zhao T., Yin L., Shi Y., Chen B., Ding Y., Lu B.: Photoresponsive soft-robotic platform: Biomimetic fabrication and remote actuation. Advanced Functional Materials, 24, 7598-7604 (2014).

https://doi.org/10.1002/adfm.201402070

[8] Ohm C., Brehmer M., Zentel R.: Liquid crystalline elastomers as actuators and sensors. Advanced Materials, 22, 3366-3387 (2010). https://doi.org/10.1002/adma.200904059

[9] Chen L., Weng M., Zhou P., Zhang L., Huang Z., Zhang W.: Multi-responsive actuators based on a graphene oxide composite: Intelligent robot and bioinspired applications. Nanoscale, 9, 9825-9833 (2017). https://doi.org/10.1039/c7nr01913k

[10] Hu Y., Wu G., Lan T., Zhao J., Liu Y., Chen W.: A graphene-based bimorph structure for design of high performance photoactuators. Advanced Materials, 27, 7867-7873 (2015). https://doi.org/10.1002/adma.201502777

[11] Zong L., Li M., Li C.: Bioinspired coupling of inorganic layered nanomaterials with marine polysaccharides for efficient aqueous exfoliation and smart actuating hybrids. Advanced Materials, 29, 1604691/1-1604691/8 (2017). https://doi.org/10.1002/adma.201604691

[12] Hines L., Petersen K., Lum G. Z., Sitti M.: Soft actuators for small-scale robotics. Advanced Materials, 29, 1603483/1-1603483/43 (2017).

https://doi.org/10.1002/adma.201603483
[13] Vantomme G., Gelebart A. H., Broer D. J., Meijer E. W.: A four-blade light-driven plastic mill based on hydrazone liquid-crystal networks. Tetrahedron, 73, 49634967 (2017). https://doi.org/10.1016/j.tet.2017.06.041

[14] Bisoyi H. K., Urbas A. M., Li Q.: Soft materials driven by photothermal effect and their applications. Advanced Optical Materials, 6, 1800458/1-1800458/21 (2018). https://doi.org/10.1002/adom.201800458

[15] Li M-H., Keller P.: Artificial muscles based on liquid crystal elastomers. Philosophical Transactions of The Royal Society - Mathematical, Physical and Engineering Sciences, 364, 2763-2777 (2006).

https://doi.org/10.1098/rsta.2006.1853

[16] Mirfakhrai T., Madden J. D. W., Baughman R. H.: Polymer artificial muscles. Materials Today, 10, 30-38 (2007). https://doi.org/10.1016/S1369-7021(07)70048-2

[17] Islam M. R., Li X., Smyth K., Serpe M. J.: Polymerbased muscle expansion and contraction. Angewandte Chemie International Edition, 52, 10330-10333 (2013). https://doi.org/10.1002/anie.201303475

[18] Ariano P., Accardo D., Lombardi M., Bocchini S., Draghi L., de Nardo L., Fino P.: Polymeric materials as artificial muscles: An overview. Journal of Applied Biomaterials and Functional Materials, 13, 1-9 (2015). https://doi.org/10.5301/jabfm.5000184

[19] Li X., Serpe M. J.: Understanding and controlling the self-folding behavior of poly ( $n$-isopropylacrylamide) microgel-based devices. Advanced Functional Materials, 24, 4119-4126 (2014). https://doi.org/10.1002/adfm.201400201

[20] Davis K. A., Burke K. A., Mather P. T., Henderson J. H.: Dynamic cell behavior on shape memory polymer substrates. Biomaterials, 32, 2285-2293 (2011). https://doi.org/10.1016/j.biomaterials.2010.12.006

[21] Le D. M., Kulangara K., Adler A. F., Leong K. W., Ashby V. S.: Dynamic topographical control of mesenchymal stem cells by culture on responsive poly( $\varepsilon$ caprolactone) surfaces. Advanced Materials, 23, 32783283 (2011). https://doi.org/10.1002/adma.201100821

[22] Li J., Shim J., Deng J., Overvelde J. T. B., Zhu X., Bertoldi K., Yang S.: Switching periodic membranes via pattern transformation and shape memory effect. Soft Matter, 8, 10322-10328 (2012). https://doi.org/10.1039/c2sm25816a

[23] Brosnan S. M., Brown A. H., Ashby V. S.: It is the outside that counts: Chemical and physical control of dynamic surfaces. Journal of the American Chemical Society. 135, 3067-3072 (2013). https://doi.org/10.1021/ja308080g

[24] Ebara M., Uto K., Idota N., Hoffman J. M., Aoyagi T.: Shape-memory surface with dynamically tunable nanogeometry activated by body heat. Advanced Materials, 24, 273-278 (2012). https://doi.org/10.1002/adma.201102181 
[25] Seyedin M. Z., Razal J. M., Innis P. C., Wallace G. G.: Strain-responsive polyurethane/PEDOT:PSS elastomeric composite fibers with high electrical conductivity. Advanced Functional Materials, 24, 2957-2966 (2014). https://doi.org/10.1002/adfm.201303905

[26] Mu T., Liu L., Lan X., Liu Y., Leng J.: Shape memory polymers for composites. Composites Science and Technology, 160, 169-198 (2018). https://doi.org/10.1016/j.compscitech.2018.03.018

[27] Zhang W., Zhang F., Lan X., Leng J., Wu A. S., Bryson T. M., Cotton C., Gu B., Sun B., Chou T-W.: Shape memory behavior and recovery force of $4 \mathrm{D}$ printed textile functional composites. Composites Science and Technology, 160, 224-230 (2018). https://doi.org/10.1016/j.compscitech.2018.03.037

[28] Chung T., Rorno-Uribe A., Mather P. T.: Two-way reversible shape memory in a semicrystalline network. Macromolecules, 41, 184-192 (2008).

https://doi.org/10.1021/ma071517z

[29] Westbrook K. K., Parakh V., Chung T., Mather P. T., Wan L. C., Dunn M. L., Qi J. H.: Constitutive modeling of shape memory effects in semicrystalline polymers with stretch induced crystallization. Journal of Engineering Materials and Technology, 132, 041010/1041010/9 (2010).

https://doi.org/10.1115/1.4001964

[30] Li J., Rodgers W. R., Xie T.: Semi-crystalline two-way shape memory elastomer. Polymer, 52, 5320-5325 (2011).

https://doi.org/10.1016/j.polymer.2011.09.030

[31] Dolynchuk O., Kolesov I., Androsch R., Radusch H-J.: Kinetics and dynamics of two-way shape-memory behavior of crosslinked linear high-density and shortchain branched polyethylenes with regard to crystal orientation. Polymer, 79, 146-158 (2015).

https://doi.org/10.1016/j.polymer.2015.10.017

[32] Kolesov I., Dolynchuk O., Jehnichen D., Reuter U., Stamm M., Radusch H. J.: Changes of crystal structure and morphology during two-way shape-memory cycles in cross-linked linear and short-chain branched polyethylenes. Macromolecules, 48, 4438-4450 (2015). https://doi.org/10.1021/acs.macromol.5b00097

[33] Raquez J-M., Vanderstappen S., Meyer F., Verge P., Alexandre M., Thomassin J-M., Jérôme C., Dubois P.: Design of cross-linked semicrystalline poly( $\varepsilon$-caprolactone)-based networks with one-way and two-way shapememory properties through diels-alder reactions. Chemistry: A European Journal, 17, 10135-10143 (2011). https://doi.org/10.1002/chem.201100496

[34] Pandini S., Passera S., Messori M., Paderni K., Toselli M., Gianoncelli A., Bontempi E., Riccò T.: Two-way reversible shape memory behaviour of crosslinked poly (E-caprolactone). Polymer, 53, 1915-1924 (2012). https://doi.org/10.1016/j.polymer.2012.02.053
[35] Messori M., Esposti M. D., Paderni K., Pandini S., Passera S., Riccò T., Toselli M.: Chemical and thermomechanical tailoring of the shape memory effect in poly( $\varepsilon$-caprolactone)-based systems. Journal of Materials Science, 48, 424-440 (2013).

https://doi.org/10.1007/s10853-012-6757-8

[36] Pandini S., Baldi F., Paderni K., Messori M., Toselli M., Pilati F., Gianoncelli A., Brisotto M., Bontempi E., Riccò T.: One-way and two-way shape memory behaviour of semi-crystalline networks based on sol-gel cross-linked poly( $\varepsilon$-caprolactone). Polymer, 54, 4253-4265 (2013). https://doi.org/10.1016/j.polymer.2013.06.016

[37] Pandini S., Dioni D., Paderni K., Messori M., Toselli M., Bontempi E., Riccò T.: The two-way shape memory behaviour of crosslinked poly( $\varepsilon$-caprolactone) systems with largely varied network density. Journal of Intelligent Material Systems and Structures, 27, 1388-1403 (2016).

https://doi.org/10.1177/1045389X15591384

[38] Huang M-M., Dong X., Liu W-L, Gao X., Wang D-J.: Recent progress in two-way shape memory crystalline polymer and its composites. Acta Polymerica Sinica, 4, 563-579 (2014).

https://doi.org/10.11777/j.issn1000-3304.2017.16229

[39] Bai Y., Zhang X., Wang H., Wang T.: A tough shape memory polymer with triple-shape memory and twoway shape memory properties. Journal of Materials Chemistry A, 2, 4771-4778 (2014). https://doi.org/10.1039/C3TA15117D

[40] Ma L., Zhao J., Wang X., Chen M., Liang Y., Wang Z., Yu Z., Hedden R. C.: Effects of carbon black nanoparticles on two-way reversible shape memory in crosslinked polyethylene. Polymer, 56, 490-497 (2015). https://doi.org/10.1016/j.polymer.2014.11.036

[41] Zotzmann J., Behl M., Hofmann D., Lendlein A.: Reversible triple-shape effect of polymer networks containing polypentadecalactone- and poly( $\varepsilon$-caprolactone)segments. Advanced Materials, 22, 3424-3429 (2010). https://doi.org/10.1002/adma.200904202

[42] Bothe M., Pretsch T.: Two-way shape changes of a shape-memory poly(ester urethane). Macromolecular Chemistry and Physics, 213, 2378-2385 (2012).

https://doi.org/10.1002/macp.201200096

[43] Hong S. J., Yu W-R., Youk J. H.: Two-way shape memory behavior of shape memory polyurethanes with a bias load. Smart Materials and Structures, 19, 035022/1035022/9 (2010). https://doi.org/10.1088/0964-1726/19/3/035022

[44] Chen S., Hu J., Zhuo H.: Properties and mechanism of two-way shape memory polyurethane composites. Composites Science and Technology, 70, 1437-1443 (2010). https://doi.org/10.1016/j.compscitech.2010.01.017

[45] Chen S., Hu J., Zhuo H., Zhu Y.: Two-way shape memory effect in polymer laminates. Materials Letters, 62, 4088-4090 (2008). https://doi.org/10.1016/j.matlet.2008.05.073 
[46] Stroganov V., Al-Hussein M., Sommer J-U., Janke A., Zakharchenko S., Ionov L.: Reversible thermosensitive biodegradable polymeric actuators based on confined crystallization. Nano Letters, 15, 1786-1790 (2015). https://doi.org/10.1021/n15045023

[47] Tamagawa H.: Thermo-responsive two-way shape changeable polymeric laminate. Materials Letters, 64, 749-751 (2010). https://doi.org/10.1016/j.matlet.2009.12.053

[48] Jiu H., Jiao H., Zhang L., Zhang S., Zhao Y.: Graphenecrosslinked two-way reversible shape memory polyurethane nanocomposites with enhanced mechanical and electrical properties. Journal of Materials Science: Materials in Electronics, 27, 10720-10728 (2016). https://doi.org/10.1007/s10854-016-5173-2

[49] Pei Z., Yang Y., Chen Q., Terentjev E. M., Wei Y., Ji Y.: Mouldable liquid-crystalline elastomer actuators with exchangeable covalent bonds. Nature Materials, 13, 36-41 (2014). https://doi.org/10.1038/NMAT3812

[50] Hanzon D. W., Traugutt N. A., McBride M. K., Bowman C. N., Yakacki C. M., Yu K.: Adaptable liquid crystal elastomers with transesterification-based bond exchange reactions. Soft Matter, 14, 951-960 (2018). https://doi.org/10.1039/c7sm02110k

[51] Wang Y., Huang X., Zhang J., Bi M., Zhang J., Niu H., Li C., Yu H., Wang B., Jiang H.: Two-step crosslinked liquid-crystalline elastomer with reversible two-way shape memory characteristics. Molecular Crystals and Liquid Crystals, 650, 13-22 (2017). https://doi.org/10.1080/15421406.2017.1318025

[52] Tian H., Wang Z., Chen Y., Shao J., Gao T., Cai S.: Polydopamine-coated main-chain liquid crystal elastomer as optically driven artificial muscle. ACS Applied Materials and Interfaces, 10, 8307-8316 (2018). https://doi.org/10.1021/acsami.8b00639

[53] Wu Y., Hu J., Han J., Zhu Y., Huang H., Li J., Tang B.: Two-way shape memory polymer with 'switch-spring' composition by interpenetrating polymer network. Journal of Materials Chemistry A, 2, 18816-18822 (2014). https://doi.org/10.1039/c4ta03640a

[54] Meng Y., Jiang J., Anthamatten M.: Shape actuation via internal stress-induced crystallization of dual-cure networks. ACS Macro Letters, 4, 115-118 (2015). https://doi.org/10.1021/mz500773v

[55] Jin B., Song H., Jiang R., Song J., Zhao Q., Xie T.: Programming a crystalline shape memory polymer network with thermo- and photo-reversible bonds toward a single-component soft robot. Science Advances, 4, 3865/1$3865 / 6$ (2018).

https://doi.org/10.1126/sciadv.aao3865
[56] Fan L. F., Rong M. Z., Zhang M. Q., Chen X. D.: Dynamic reversible bonds enable external stress-free twoway shape memory effect of a polymer network and the interrelated intrinsic self-healability of wider crack and recyclability. Journal of Materials Chemistry A, 6, 16053-16063 (2018).

https://doi.org/10.1039/c8ta05751f

[57] Fan L. F., Rong M. Z., Zhang M. Q., Chen X. D.: A facile approach toward scalable fabrication of reversible shapememory polymers with bonded elastomer microphases as internal stress provider. Macromolecular Rapid Communications, 38, 1700124/1-1700124/6 (2017). https://doi.org/10.1002/marc.201700124

[58] Fan L. F., Rong M. Z., Zhang M. Q., Chen X. D.: A very simple strategy for preparing external stress-free twoway shape memory polymers by making use of hydrogen bonds. Macromolecular Rapid Communications, 39, 1700714/1-1700714/7 (2018).

https://doi.org/10.1002/marc.201700714

[59] Fan L. F., Rong M. Z., Zhang M. Q., Chen X. D.: Repeated intrinsic self-healing of wider cracks in polymer via dynamic reversible covalent bonding molecularly combined with a two-way shape memory effect. ACS Applied Materials and Interfaces, 10, 38538-38546 (2018).

https://doi.org/10.1021/acsami.8b15636

[60] Lu L., Li G.: One-way multishape-memory effect and tunable two-way shape memory effect of ionomer poly(ethylene-co-methacrylic acid). ACS Applied Materials and Interfaces, 8, 14812-14823 (2016).

https://doi.org/10.1021/acsami.6b04105

[61] Behl M., Kratz K., Zotzmann J., Nöchel U., Lendlein A.: Reversible bidirectional shape-memory polymers. Advanced Materials, 25, 4466-4469 (2013). https://doi.org/10.1002/adma.201300880

[62] Wang K., Jia Y-G., Zhu X. X.: Two-way reversible shape memory polymers made of cross-linked cocrystallizable random copolymers with tunable actuation temperatures. Macromolecules, 50, 8570-8579 (2017). https://doi.org/10.1021/acs.macromol.7b01815

[63] Gao Y., Liu W., Zhu S.: Polyolefin thermoplastics for multiple shape and reversible shape memory. ACS Applied Materials and Interfaces, 9, 4882-4889 (2017). https://doi.org/10.1021/acsami.6b14728

[64] Bothe M., Pretsch T.: Bidirectional actuation of a thermoplastic polyurethane elastomer. Journal of Materials Chemistry A, 1, 14491-14497 (2013).

https://doi.org/10.1039/c3ta13414h

[65] Behl M., Kratz K., Noechel U., Sauter T., Lendlein A.: Temperature-memory polymer actuators. Proceedings of the National Academy of Sciences of the United States of America. 110, 12555-12559 (2013). https://doi.org/10.1073/pnas.1301895110 
[66] Zhou J., Turner S. A., Brosnan S. M., Li Q., Carrillo J-M. Y., Nykypanchuk D., Gang O., Ashby V. S., Dobrynin A. V., Sheiko S. S.: Shapeshifting: Reversible shape memory in semicrystalline elastomers. Macromolecules, 47, 1768-1776 (2014).

https://doi.org/10.1021/ma4023185

[67] Turner S. A., Zhou J., Sheiko S. S., Ashby V. S.: Switchable micropatterned surface topographies mediated by reversible shape memory. ACS Applied Materials and Interfaces, 6, 8017-8121 (2014).

https://doi.org/10.1021/am501970d

[68] Gong T., Zhao K., Wang W., Chen H., Wang L., Zhou S.: Thermally activated reversible shape switch of polymer particles. Journal of Materials Chemistry B, 2, 6855 6866 (2014).

https://doi.org/10.1039/c4tb01155d

[69] Saatchi M., Behl M., Nöchel U., Lendlein A.: Copolymer networks from oligo( $\varepsilon$-caprolactone) and $n$-butyl acrylate enable a reversible bidirectional shape-memory effect at human body temperature. Macromolecular Rapid Communications, 36, 880-884 (2015). https://doi.org/10.1002/marc.201400729

[70] Li Q., Zhou J., Vatankhah-Varnoosfaderani M., Nykypanchuk D., Gang O., Sheiko S. S.: Advancing reversible shape memory by tuning the polymer network architecture. Macromolecules, 49, 1383-1391 (2016). https://doi.org/10.1021/acs.macromol.5b02740

[71] Zharinova E., Heuchel M., Weigel T., Gerber D., Kratz K., Lendlein A.: Water-blown polyurethane foams showing a reversible shape-memory effect. Polymer, 8 , 412-434 (2016).

https://doi.org/10.3390/polym8120412

[72] Yang G., Liu X., Tok A. L. Y., Lipik V.: Body temperature-responsive two-way and moisture-responsive oneway shape memory behaviors of poly(ethylene glycol)based networks. Polymer Chemistry, 8, 3833-3840 (2017). https://doi.org/10.1039/c7py00786h

[73] Huang Y. N., Fan L. F., Rong M. Z., Zhang M. Q., Gao Y. M.: External stress-free reversible multiple shape memory polymers. ACS Applied Materials and Interfaces, 11, 31346-31355 (2019).

https://doi.org/10.1021/acsami.9b10052

[74] Fan L. F., Huang Y. N., Rong M. Z., Zhang M. Q., Chen $\mathrm{X}$. Imparting external stress-free two-way shape memory effect to commodity polyolefins by manipulation of their hierarchical structures. ACS Macro Letters, 8, 1141-1146 (2019).

https://doi.org/10.1021/acsmacrolett.9b00467
[75] Gagnon K. D., Lenz R. W., Farris R. J., Fuller R. C.: Chemical modification of bacterial elastomers: 1 . Peroxide crosslinking. Polymer, 35, 4358-4367 (1994). https://doi.org/10.1016/0032-3861(94)90093-0

[76] Akiba M., Hashim A. S.: Vulcanization and crosslinking in elastomers. Progress in Polymer Science, 22, 475521 (1997).

https://doi.org/10.1016/S0079-6700(96)00015-9

[77] Loan L. D.: Mechanism of peroxide vulcanization of elastomers. Rubber Chemistry and Technology, 40, 149-176 (1967).

https://doi.org/10.5254/1.3539040

[78] Unger M., Siesler H. W.: In situ orientation studies of a poly(3-hydroxybutyrate)/poly( $\varepsilon$-caprolactone) blend by rheo-optical Fourier transform infrared spectroscopy and two-dimensional correlation spectroscopic analysis. Applied Spectroscopy, 63, 1351-1355 (2009). https://doi.org/10.1366/000370209790109030

[79] Hakme C., Stevenson I., Voice A., Lespinasse G., Seytre G., David L.: Orientation of uniaxially stretched poly (ethylene naphthalene 2,6-dicarboxylate) films by polarized infrared spectroscopy. Journal of Polymer Science Part B: Polymer Physics, 45, 1950-1958 (2007). https://doi.org/10.1002/polb.21219

[80] Sekkar V., Narayanaswamy K., Scariah K. J., Nair P. R., Sastri K. S., Ang H. G.: Evaluation by various experimental approaches of the crosslink density of urethane networks based on hydroxyl-terminated polybutadiene. Journal of Applied Polymer Science, 103, 3129-3133 (2007).

https://doi.org/10.1002/app.24751

[81] Crescenzi V., Manzini G., Calzolari G., Borri C.: Thermodynamics of fusion of poly- $\beta$-propiolactone and poly- $\varepsilon$-caprolactone. Comparative analysis of the melting of aliphatic polylactone and polyester chains. European Polymer Journal, 8, 449-463 (1972). https://doi.org/10.1016/0014-3057(72)90109-7

[82] Li F., Hou J., Zhu W., Zhang X., Xu M., Luo X., Ma D., Kim B. K.: Crystallinity and morphology of segmented polyurethanes with different soft-segment length. Journal of Applied Polymer Science, 62, 631-638 (1996). https://doi.org/10.1002/(SICI)10974628(19961024)62:4<631::AID-APP6>3.0.CO;2-U

[83] Pan Z. R.: Polymer chemistry. Chemical Industry Press, China (2013). 